ORIGINAL ARTICLE

\title{
Combined Effects of Medicinal Plants on Induced Upper Gastrointestinal Tract Injury in Wistar Rats
}

\author{
Frederick Akinbo ${ }^{1,}$ Gerald Eze $^{2}$
}

\begin{abstract}
BACKGROUND: Herbal medicines are now recently used as treatment options. This study was conducted to determine the effect of the combination therapy of medicinal herbs in the treatment of induced gastrointestinal injury among albino wistar rats.

METHODS: A total of 60 Albino Wistar rats of both sexes weighing between $130 \mathrm{~g}-150 \mathrm{~g}$ were used. The control groups which consisted of negative control groups received $1 \mathrm{ml}$ of normal saline while the positive control group was given 20mg/kg of indomethacin and sacrificed after 6 hours. Those in the test group were given $20 \mathrm{mg} / \mathrm{kg}$ of indomethacin, treated in different doses of single and combined extracts of Allium sativum, Brassica oleracea and Aloe barbadensis at 100mg/kg, 200mg/kg and 300mg/kg body weights, twice daily for 8 days and sacrificed.

RESULTS: There was no visible sign of ulceration or perforation observed on the stomach and duodenum when compared with the control. The combination of all three plant extracts at different concentrations ranging from $100-300 \mathrm{mg} / \mathrm{kg}$ cleared all visible ulcers and perforations on the stomach of wistar rats. Similarly, all ulcers in the duodenum of indomethacin induced wistar rats were cleared by the combination of the three extracts. The sections of rat stomach and duodenum given $100 \mathrm{mg} / \mathrm{kg}$ herbal cocktail and indomethacin showed normal mucosa.

CONCLUSIONS: A mixture of the three herbs at 300mg/kg was better in healing gastric and duodenal ulcers. The mixture of the three plants extracts exhibit good anti-ulcer activity that warrants further studies.
\end{abstract}

KEYWORDS: Medicinal plants, gastrointestinal tract injury, wistar rats

DOI: http://dx.doi.org/10.4314/ejhs.v26i6.11

\section{INTRODUCTION}

Herbal medicines are used as treatment options by as many as $50 \%$ of the western population, where approximately $10 \%$ are for the treatment or prevention of digestive disorders (1). Considering the morbidity attributed to peptic ulcer disease and dyspepsia globally, cheap and readily available treatments will always be in demand particularly for the people of developing countries (2). The World Health Organization (WHO) defines herbal medicines as finished labeled medicinal products which contain active ingredients, aerial or underground parts of plants or other plant materials orcombination(s) of such whether in the crude state or as plant preparations (3).
Allium sativum is grown globally and is widely used for its pungent flavour as a seasoning (4). It also represents an important source of antioxidant phytochemicals like diallyl sulfide, Sallylmercaptocysteine and ajoene that are the optimal assurance for neutralizing free radicalmediated inflammation. The plant has hepatoprotective, neuroprotective, genoprotective, immunoprotective, and antioxidative activities $(5,6,7)$. The garlic plant's bulb is the most commonly used part of the plant (8). The acclaimed medicinal uses of garlic include diaphoretic, diuretic, expectorant, stimulant, antiulcer, antimicrobial, antiviral, antifungal, antiparasitic and antiseptic $(9,10)$.

\footnotetext{
${ }^{1}$ Department of Medical Laboratory Science, University of Benin, Benin City, Nigeria

${ }^{2}$ Department of Anatomy, University of Benin, Benin City, Nigeria

Corresponding Author: Frederick O. Akinbo, Email: fgbengang@yahoo.com
} 
Brassica oleracea L (cabbage) is a green or purple biennial plant that contains proteins (principally amino acids and essential fatty acids), vitamins and minerals $(11,12)$. It is a good source of vitamins $\mathrm{C}, \mathrm{K}$ and $\mathrm{B}_{6}$, containing more than $20 \%$ of the daily value for each nutrient per meal (13). It contains significant amounts of glutamine that has anti-inflammatory properties (14).

Aloe plants have been used medicinally for centuries, amongst the species is Aloe barbadensis, which is commonly referred to as Aloe vera. It is one of the most widely used healing plants in man (15). Its major constituents are water and polysaccharides-pectins, hemicelluloses, glucomannan, acemannan and mannose derivatives (16). It is used as a remedy against a variety of skin disorders (17); the leaf exudate possesses anti-diabetic (18), cardiac stimulatory activity (19), anti-inflammatory and promotes wound healing (20).

The mechanism of herb-induced gastro protection varies based on the chemical constituents of the herbs. The antisecretory, cytoprotective and antioxidant activities (isolated or in combination) are responsible for gastric mucosal protection (21). Due to the global economic down turn, drugs are now expensive and may present many side effects during treatment of any disorders. Plants that have curative properties are used to improve cure and prevent diseases such as diarrhea, stomach disorder, asthma, hypertension and peptic ulcers (22). Information is lacking on the effect of the combination of medicinal herbs to treat peptic ulcers. Against this background, this study was conducted to determine the effect of the combination therapy of medicinal herbs in the treatment of induced upper gastrointestinal injury among albino wistar rats.

\section{MATERIALS AND METHODS}

Plant collection and extraction: Allium sativum, Brassica oleracea and Aloe barbadensis were purchased from a vegetable market in Benin City, Nigeria. The plant samples were authenticated at the Department of Pharmacognosy of University of Benin, Benin City, Edo State. Two hundred and fifty grams of each of the three plants were washed in water and crushed separately to semiaqueous form using a mechanical blender. About $500 \mathrm{mls}$ of distilled water was added separately to each and agitated for 4 hours and left overnight.
The resultant filtrates were evaporated to dryness in an oven at $40^{\circ} \mathrm{C}$; the residues were re-suspended and used as the aqueous extract. Of these powders, 100,200 and $300 \mathrm{mg} / \mathrm{kg}$ body weights were prepared in $100 \mathrm{ml}$ of distilled water before use (23). Each rat received $1 \mathrm{ml}$ of each extract with the aid of a gavage while they were given their normal feed (livestock grower's marsh) and drinking water ad libitum.

Animal: A total of 60 albino wistar rats of both sexes weighing between $130 \mathrm{~g}-150 \mathrm{~g}$ were used. They were randomly divided into groups and kept under standard conditions of temperature and humidity. The rats were allowed to acclimatize for two weeks in the animal house at the Faculty of Life Sciences, University of Benin in Nigeria prior to the experiments. The rats were selected into fifteen study groups: two control groups and thirteen treated groups (4 rats of each). The National and Institutional Guidelines for the Protection of Animal were followed in handling the rats. Food was withdrawn 24 hours prior to the inducement of ulcer on the rats while water was maintained while $20 \mathrm{mg} / \mathrm{kg}$ of indomethacin in 1 $\mathrm{ml}$ of distilled water was administered orally to each rat using gavage except the negative control group.

Study design: This study was conducted between April and September in 2015. The control groups which consisted of negative control group received $1 \mathrm{ml}$ of normal saline while the positive control group was given $20 \mathrm{mg} / \mathrm{kg}$ of indomethacin and sacrificed after 6 hours (groups 1 and 2). Group 3 was administered $20 \mathrm{mg} / \mathrm{kg}$ of indomethacin and treated with aqueous extract of Allium sativum $(100 \mathrm{mg} / \mathrm{kg})$ body weight), twice daily for 8 days and sacrificed. Group 4 was given $20 \mathrm{mg} / \mathrm{kg}$ of indomethacin and treated with aqueous extract of Allium sativum (200mg/kg)body weight), twice daily for 8 days and sacrificed. Group 5 received $20 \mathrm{mg} / \mathrm{kg}$ of indomethacin and treated with aqueous extract of Allium sativum $(300 \mathrm{mg} / \mathrm{kg})$ body weight), twice daily for 8 days and sacrificed. Group 6 was administered $20 \mathrm{mg} / \mathrm{kg}$ of indomethacin and treated with aqueous extract of Brassica oleracea $(100 \mathrm{mg} / \mathrm{kg})$ body weight), twice daily for 8 days and sacrificed. Group 7 got $20 \mathrm{mg} / \mathrm{kg}$ of indomethacin and treated with aqueous extract of Brassica oleracea $(200 \mathrm{mg} / \mathrm{kg})$ body weight), twice daily for 8 days and sacrificed. Group 8 was given 
$20 \mathrm{mg} / \mathrm{kg}$ of indomethacin and treated with aqueous extract of Brassica oleracea (300 mg $/ \mathrm{kg}$ )body weight), twice daily for 8 days and sacrificed. Groups $9-11$ received $20 \mathrm{mg} / \mathrm{kg}$ of indomethacin and treated with aqueous extract of Aloe barbadensis $(100 \mathrm{mg} / \mathrm{kg}, \quad 200 \mathrm{mg} / \mathrm{kg}$ and $300 \mathrm{mg} / \mathrm{kg}$ respectively)body weights), twice daily for 8 days and sacrificed. Group 12 was administered $20 \mathrm{mg} / \mathrm{kg}$ of indomethacin and treated with aqueous extract of the mixture of Allium sativum, Brassica oleracea and Aloe barbadensis (100mg/kg)body weight), twice daily for 8 days and sacrificed. Group 13 was given $20 \mathrm{mg} / \mathrm{kg}$ of indomethacin and treated with aqueous extract of the mixture of Allium sativum, Brassica oleracea and Aloe barbadensis (200mg/kg)body weight), twice daily for 8 days and sacrificed. Group 14 was administered $20 \mathrm{mg} / \mathrm{kg}$ of indomethacin and treated with aqueous extract of the mixture of Allium sativum, Brassica oleracea and Aloe barbadensis $(300 \mathrm{mg} / \mathrm{kg}$ )body weight), twice daily for 8 days and sacrificed. Group 15 had $20 \mathrm{mg} / \mathrm{kg}$ of indomethacin and afterwards treated with cimetidine $(50 \mathrm{mg} / \mathrm{kg})$ body weight $)$, twice daily for 8 days and sacrificed (24).

Ulcer index: The dissected stomachs and duodena were opened and the inner surface rinsed in saline water. Ulceration was determined using a previously described method (25). Briefly, a magnifying lens was used to measure the length of lesions within $1 \mathrm{~mm}$. Ulcer indexing was carried out using the following scoring system: $0=$ no lesion, 1 = haemorrhagic suffusions, $2=1-5$ small ulcers that are up to $3 \mathrm{~mm}$ in length, $3=$ many small ulcers more than 5 or 1 ulcer of more than $3 \mathrm{~mm}, 4=$ many ulcers of more than $3 \mathrm{~mm}, 5$ $=$ perforated ulcers.

The curative ratio was calculated using the formula below:

Curative ratio $(\mathrm{CR})=(\mathrm{LC}-\mathrm{LT} / \mathrm{LC}) \times 100$

LC: length of gastric ulcer in positive group

LT: length of gastric ulcer in treated group

Macroscopic study: The stomach and duodenum of the control and the treated groups were rinsed in normal saline and spread out with pins on a soft board. This was photographed using a Samsung digital camera to assess the lesion on the mucosa in both the control and the test groups.

Histopathological investigation:The macroscopic examined stomach and duodenum were fixed in
$10 \%$ formol saline for 24 hours. The fixed tissues were processed in an automatic tissue processor machine (Shandon 2000, Leica, Frankfurt, Germany). Tissues were dehydrated in different grades of alcohol, cleared in toluene and impregnated in molten paraffin wax for specified periods in the processor machine. Processed tissues were embedded in fresh molten paraffin wax and allowed to set. Tissue blocks were trimmed at $0 \mu$, sectioned at $3 \mu$ and sections were dried on a hotplate for 15 minutes. Sections were stained in Cole's haematoxylin and $1 \%$ aqueous eosin to demonstrate general tissue structure. Stained slides were dehydrated in various ascending grades of alcohol, cleared in xylene and mounted in Canada balsam (26). Sections were microscopically examined using x10 and x40 objective lenses.

Statistical analysis: The data obtained were expressed as Mean \pm SD and evaluated statistically using unpaired t- test. Significant difference was set at $P<0.05$.

\section{RESULTS}

In all cases $(100-300 \mathrm{mg} / \mathrm{kg})$, after 8 days of treatment, no visible macroscopic signs of ulceration or perforation were observed in all plates when compared with the control. Similar picture was observed in the duodenum as treatment with Aloe vera, cabbage and garlic eliminated all signs of gastrointestinal injury including ulcer and perforation, in the indomethacin induced wistar rats. The combination of all three plant extracts at different concentrations ranging from $100-300 \mathrm{mg} / \mathrm{kg}$ cleared all visible ulcers and perforations on the stomach of wistar rats. In the same vein, all ulcers in the duodenum of indomethacin induced wistar rats were cleared by the combination of the three extracts, and the same picture was seen irrespective of the concentrations of the combined. Cimetidine cleared all ulcers and perforations in the stomach as well as all ulcers in the duodenum.

The ulcerative index of the stomach and duodenum of indomethacin treated wistar rats were $3.0 \pm 1.0$ and $1.25 \pm 0.50$ (figures are in mean \pm standard deviation) respectively. Aloe vera, cabbage and garlic reduced the ulcerative index of the stomach and duodenum to zero. The ulcerative index after treatment with Aloe vera, cabbage and 
garlic and a combination of the three were significantly lower $(\mathrm{P}=0.02398)$ than the ulcerative index before treatment. The same picture was observed on the duodenum
$(\mathrm{P}=0.01539)$ (Table 1$)$. The curative ratio $(\%)$ of Aloe vera, cabbage and garlic and a combination of the three at different concentrations were $100 \%$ in each case.

Table 1: Effect of plant extracts on ulcerative index of the stomach and duodenum of wistar rats

\begin{tabular}{llll}
\hline \multicolumn{3}{c}{ Ulcerative index $(\mathrm{mm})$} \\
\hline Extract & Before treatment & After treatment & P value \\
\hline Stomach & & & \\
$\quad$ Aloe vera & $3.0 \pm 1.0$ & $0.0 \pm 0.0$ & 0.02398 \\
$\quad$ Cabbage & $3.0 \pm 1.0$ & $0.0 \pm 0.0$ & 0.02398 \\
$\quad$ Garlic & $3.0 \pm 1.0$ & $0.0 \pm 0.0$ & 0.02398 \\
Duodenum & $1.25 \pm 0.50$ & $0.0 \pm 0.0$ & 0.01539 \\
$\quad$ Aloe vera & $1.25 \pm 0.50$ & $0.0 \pm 0.0$ & 0.01539 \\
$\quad$ Cabbage & $1.25 \pm 0.50$ & $0.0 \pm 0.0$ & 0.01539 \\
$\quad$ Garlic & $3.0 \pm 1.0$ & $0.0 \pm 0.0$ & 0.02398 \\
Stomach & & & \\
$\quad$ AV + C + G & $1.25 \pm 0.50$ & $0.0 \pm 0.0$ & 0.012398 \\
Duodenum & AV + C + G & &
\end{tabular}

$\mathrm{AV}=$ Aloe vera; $\mathrm{C}=$ Cabbage; $\mathrm{G}=\mathrm{Garlic}$.

Figures are in mean \pm standard deviation

Figures 1 and 2 are sections of the stomach and duodenum of indomethacin induced rats showing mucosal devitalization, erosion and gastric pit (stomach) and devitalized mucosa composing of necrotic debris, inflammatory cells and granulation tissue (duodenum). The architectural structure of the stomach and duodenum was altered due to the introduction of indomethacin.

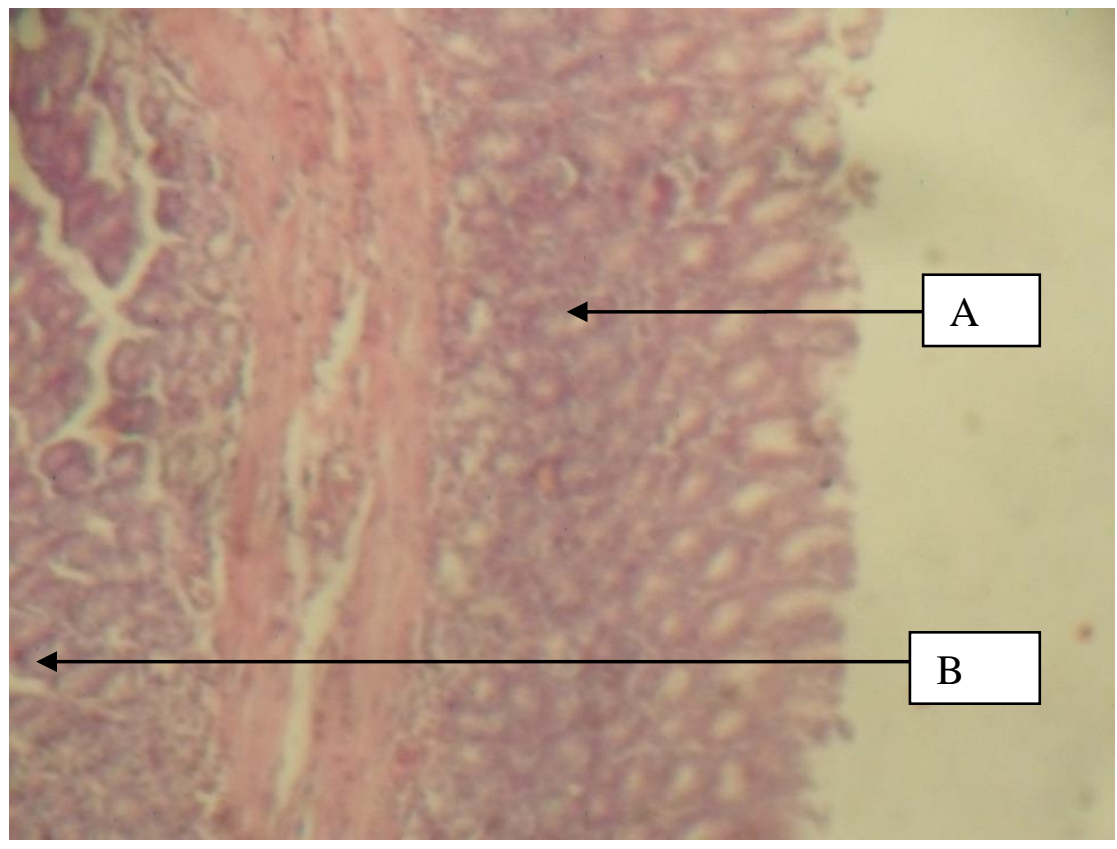

Figure 1: Stomach given 100mg/kg Herbal cocktail and Indomethacin showing A, normal mucosa and B, muscularis mucosa (H\&E x 40) 


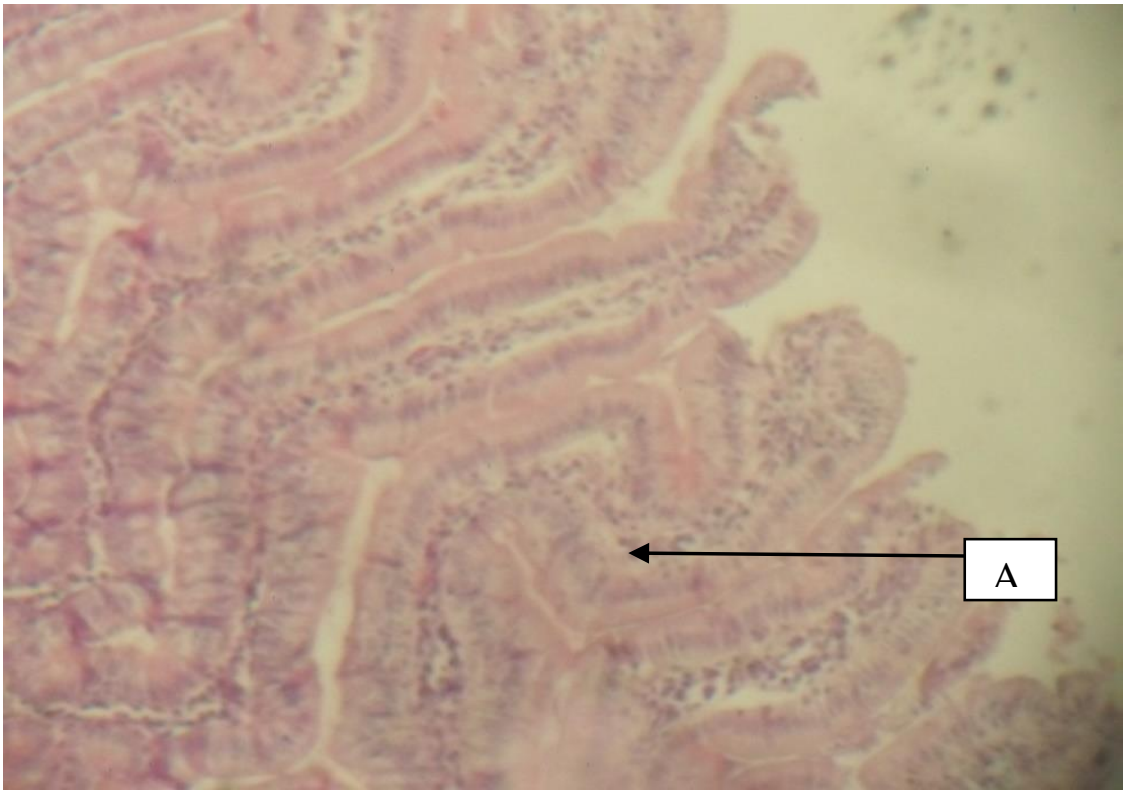

Figure 2: Duodenum given 100mg/kg cocktail and Indomethacin showing A, fairly normal mисоsa $(H \& E x 40)$

The sections of rat stomach and duodenum given $100 \mathrm{mg} / \mathrm{kg}$ herbal cocktail and indomethacin showing normal mucosa on Figures 3 and 4.
Treatment with the $100 \mathrm{mg} / \mathrm{kg}$ herbal cocktail brought about healing in both organs as shown on the sections.

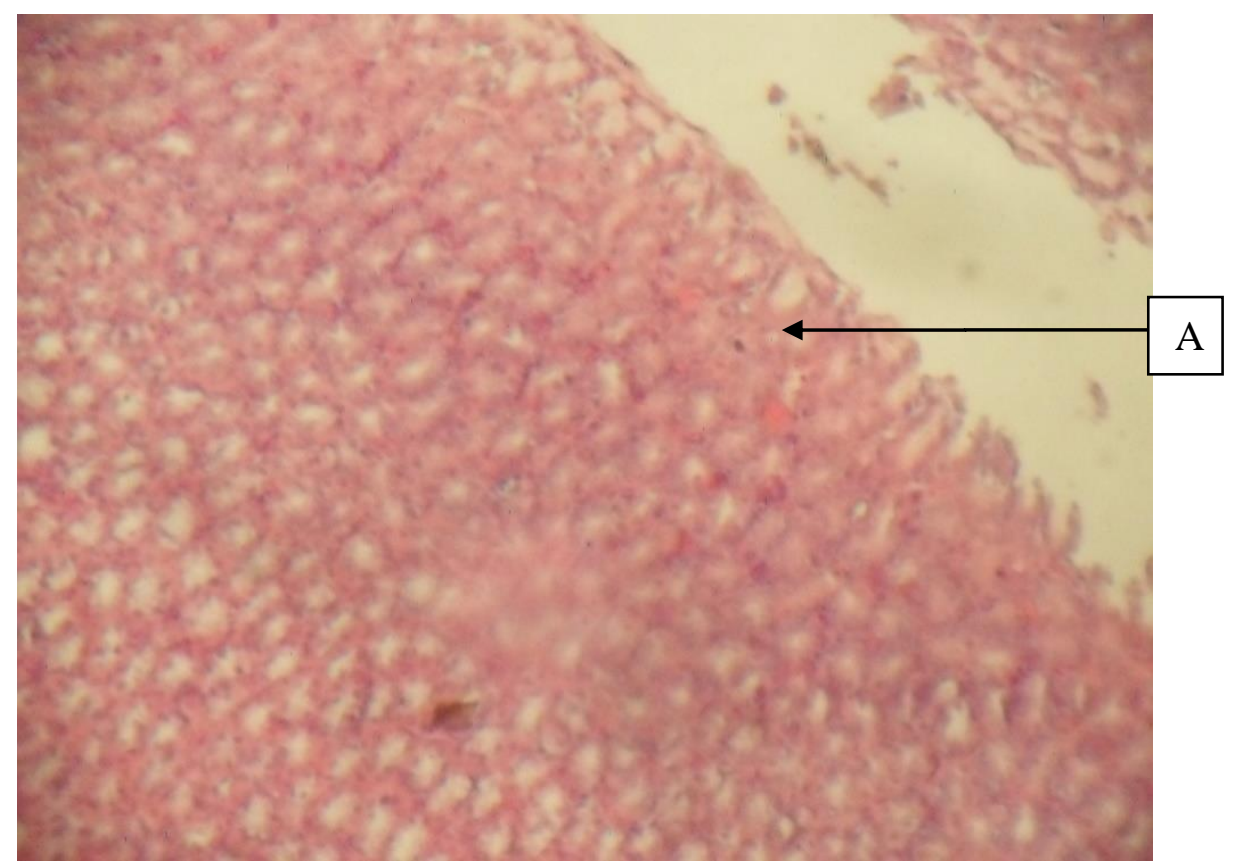

Figure 3: Stomach given 300mg/kg Herbal cocktail and Indomethacin showing A, normal mucosa (H\&E $x$ 40) 


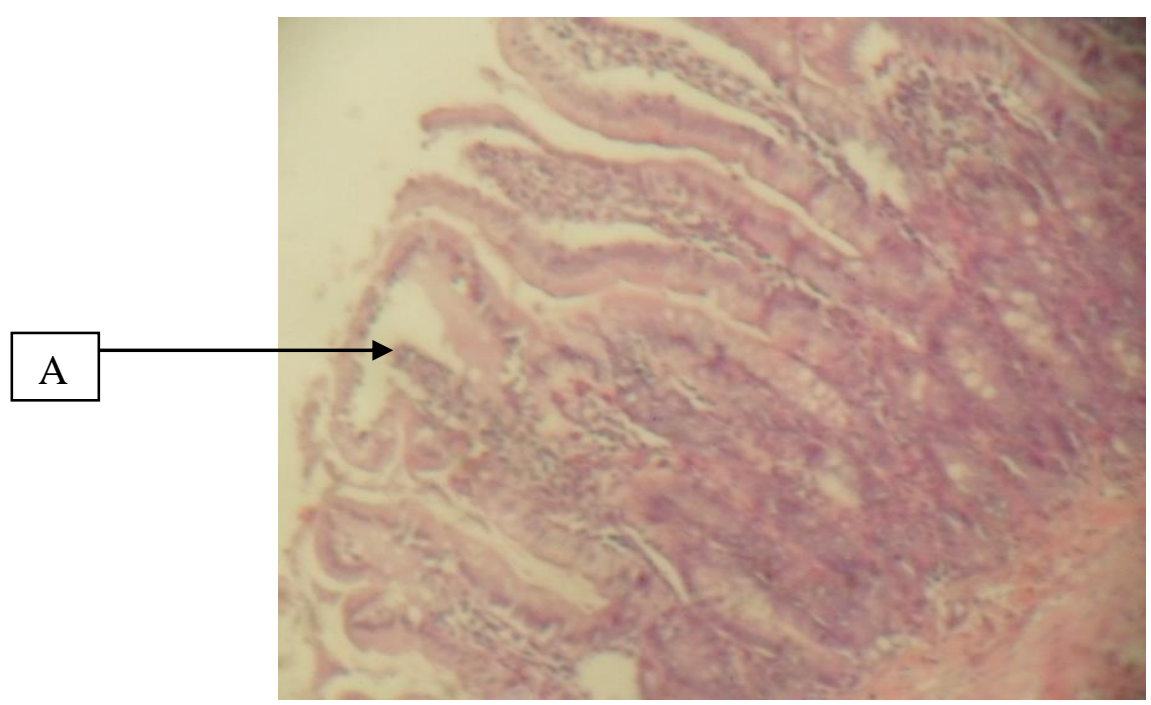

Figure 4: Duodenum given 300mg/kg herbal cocktail and indomethacin showing A, normal mucosa (H\&E $x$ 40)

Figures 5 and 6 are sections of rat stomach and duodenum given the herbal cocktail showing normal mucosa. Section of the stomach given cimetidine and indomethacin showed fairly normal mucosa. The section of rat duodenum administered cimetidine and indomethacin shows mild mucosal sloughing (figures not shown).

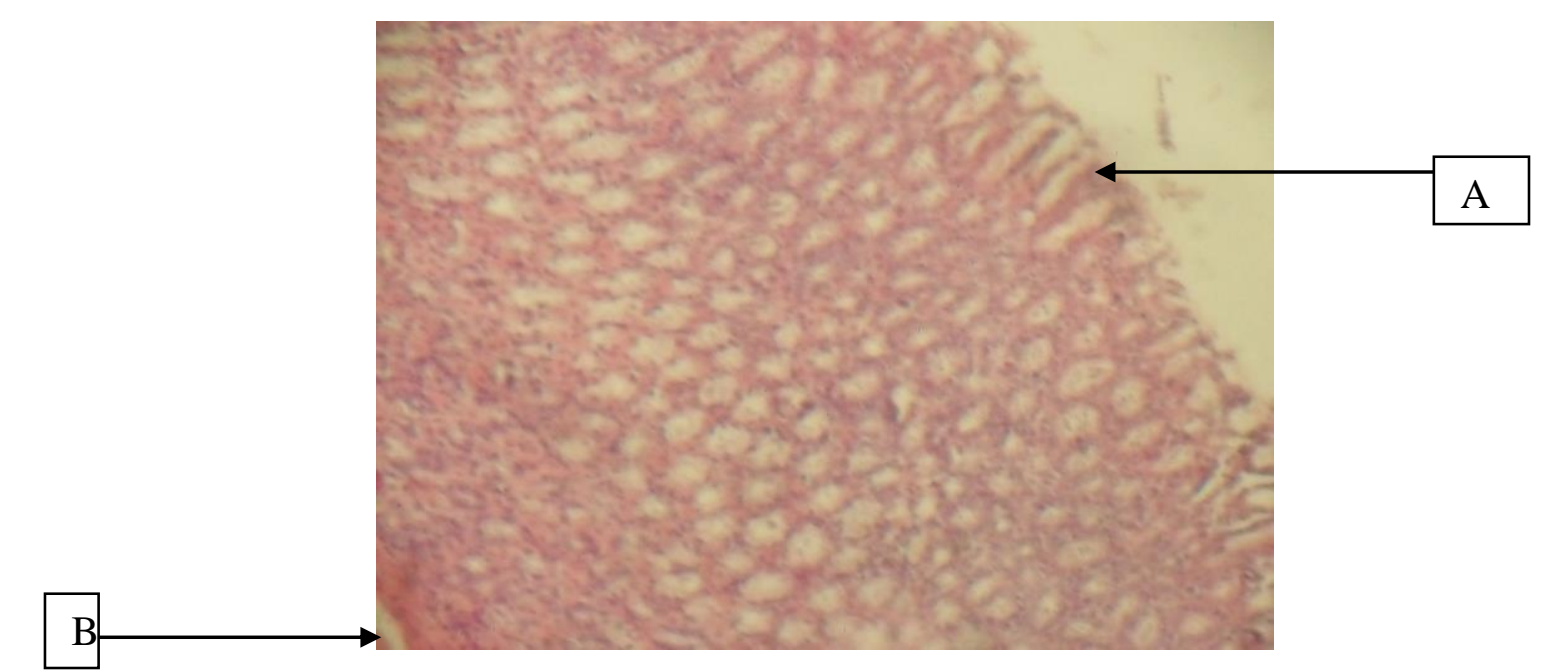

Figure 5: Stomach given cimetidine after induction showing A, fairly normal mucosa and B, muscularis mucosa $(H \& E x 40)$

\section{DISCUSSION}

The majority of preparations of remedies in peptic ulcers in previous studies involved the use of single plant $(23,27,28)$. The use of multiple therapies in traditional medicine has been shown to increase the efficacy of some herbal medicines (29). In this study, following treatment with the combination therapy of Aloe vera, cabbage and garlic, the ulcerative index was zero. Treatment with the herbal cocktail showed significant difference when compared with control in both stomach and duodenum of the wstar rats.

The use of more than one plant species to prepare as a remedy for ailments is attributed to the additive or synergistic effects that they could have during ailment treatment (30). The administration of extract of herbal mixture has also benefited ulcer healing (31) and reduced recurrence rates (32). A combination of Aloe vera, cabbage and garlic produced healing of the indomethacin induced upper gastrointestinal tract injury in this study. A similar observation was made 
elsewhere by Adnan et al. (29) where a combination of

wounds. aloe vera plant and Curcuma longa was used to treat

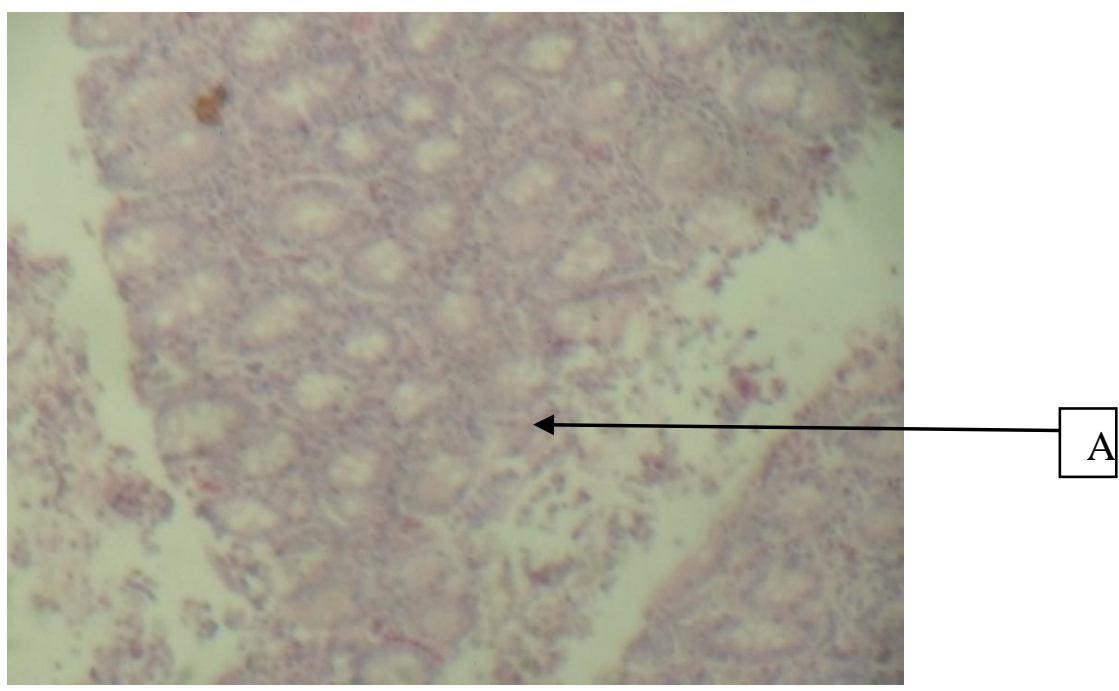

Figure 6: Duodenum given cimetidine and indomethacin showing A, mild mucosal sloughing (H\&E x 40)

Adnan et al. (29) observed that there is no consensus on the dosage and frequency of the medication among healers in Pakistan as the dosage depends on the type and severity of the illness or injury being treated. The mixture of Aloe vera, cabbage and garlic given at $100 \mathrm{mg} / \mathrm{kg}$ dosage healed gastric ulcers and perforations, and showed normal mucosa. This may indicate that all three herbal mixtures either potentiated each other's activity or acted indifferently to produce this picture. This was not observed in the duodenum as a fairly normal mucosa was seen. The reason for this is unclear and will warrant further investigation. Increase of the dosage of garlic, cabbage and Aloe vera to $300 \mathrm{mg} / \mathrm{kg}$ individually produced fairly normal mucosa of the stomach and duodenum. This may indicate the higher concentration $(200 \mathrm{mg} / \mathrm{kg})$ or that the lower concentration $(100 \mathrm{mg} / \mathrm{kg})$ would be more effective in treating gastric and duodenal ulcers. Therefore, there may be a problem with overdose, and this may be very likely in our environment where herbal remedies are not regulated and self-medication is rife. Surprisingly, the mixture of garlic, cabbage and Aloe vera at a dosage of $300 \mathrm{mg} / \mathrm{kg}$ produced normal mucosa in both the stomach and the duodenum. This may indicate that the harmful effects of individual herbal remedies at higher concentrations were diluted out in the mixture. Therefore, the mixture of the three herbal remedies used in this study is recommended for use. However, toxicity studies are needed before clinical trials and final approval.

In contrast, cimetidine, a drug used for treatment of ulcers produced fairly normal mucosa in the stomach and mild mucosa sloughing in the duodenum of the adult wistar rats. This indicates that the herbal remedies were better than cimetidine in the treatment of gastric and duodenal ulcers in the albino rats. The efficacy of some herbal medicines is superior to that of conventional drugs (33). This finding agrees with a herbal extract from Alchornea glandulosa that produced a higher curative rate than cimetidine (34).

In conclusion, a mixture of the three herbs at $300 \mathrm{mg} / \mathrm{kg}$ was better in healing gastric and duodenal ulcers in the albino rats. The mixture of the three plants exhibited good anti-ulcer activity that warrants further studies.

\section{REFERENCES}

1. Langmead L, Rampton DS. Herbal treatment in gastrointestinal and liver disease - benefits and dangers. Aliment Pharmacol Ther 2001; 15:1239.

2. Thamlikitkul V, Banyapraphatsara N, Dechatiwongse T, Theerapong S, Chantrakul C, Thanaveersuwan T. Randomized double blind study of Curcoma domestica Val. For dyspepsia. J Med Assoc Thai 1989; 72:613-20.

3. WHO. Guidelines for the assessment of Herbal medicines. 1991 World Health Organisation. Geneva, 1995.

4. Simonetti G. Simon \& Schuster's Guide to Herbs and Spices, Simon \& Schuster, Inc., 1990; 57.

5. Rahman K. Garlic and aging: new insights into an old remedy. Ageing Res Rev 2003; 2(1):39-56.

6. Amagase $H$. Clarifying the real bioactive constituents of garlic. J Nutri 2006; 136:716-25.

7. Borek C. Garlic reduces dementia and heartdisease risk. J Nutri 2006; 136(3):810-12.

8. Macpherson LJ, Geierstanger BH, Viswanath V, et al.; The pungency of garlic: Activation of TRPA1 
and TRPV1 in response to allicin. Current Biol 2005; 15 (10):929-34.

9. Ried K, Frank OR, Stocks NP. Aged garlic extract lowers blood pressure in patients with treated but uncontrolled hypertension: a randomised controlled trial. Maturitas 2010; 67(2):144-50.

10. Deein W, Thepsithar C, Thongpukdee A, Tippornwong S. Growth of Chrysanthemum Explants on MS Medium Sterilized by Disinfectants and Essential Oils. Intern J Biosci Biochem Bioinfor 2013; 609:105-9.

11. Janick J. Plant Breeding Reviews. California, CA: John Wiley and Sons, 2011; 51.

12. Borrelli F, Izzo AA. The plant kingdom as a source of anti-ulcer remedies. Phytother Res 2000; 14:581.

13. Wong BB, Koh S, Hegney DG, He H-G. The effectiveness of cabbage leaf application (treatment) on pain and hardness in breast engorgement and its effect on the duration of breastfeeding. JBI Database Sys Rev Implem Rep 2012; 10(20):1185-1213.

14. Carvalho CA, Silva MB, Oliveira TG, Lima JM, Rosa MB. Spectrometric study at different phenologic stages of the cabbage (Brassica oleraceae var. capitata). Rev Bras Farmacogn 2008; 18:249-57.

15. Moon EJ, Lee YM, Lee $\mathrm{OH}$, et al.; A novel angiogenic factor derived from Aloe vera gel: betasitosterol, a plant sterol. Angiogenesis 1999;3: 117.

16. Davis RH, Donato JJ, Hartman GM, Haas RC. Anti-inflammatory and wound healing activity of a growth substance in Aloe vera. J Am Pediatr Med Assoc 1994; 84: 77-81.

17. Capasso F, Gaginella TS. (1997). Laxatives: a practice guide. Milan, Springer Italia, 1997; 145.

18. Ghannam N, Kingston M, Al-Meshaal IA, Tariq M, Parman NS, Woodhouse N. The antidiabetic activity of aloes: preliminary clinical and experimental observations. Horm Res 1986; 24:288-94.

19. Yagi A, Shibata S, Nishioka I, Iwadare S, Ishida Y. Cardiac stimulant action of constituents of Aloe saponaria. J Pharm Sci 1982; 71: 739-41.

20. Eamlamnam K, Patumraj S, Visedopas N, ThongNgam D. Effects of Aloe vera and sucralfate on gastric microcirculatory changes, cytokine levels and gastric ulcer healing in rats. World $\mathbf{J}$ Gastroenterol 2006; 12(13):2034-39.

21. Al Mofleh IA. Spices, herbal xenobiotics and the stomach: Friends or foes? World J Gastroenterol 2010; 16(22):2710-19.

22. Martin KW, Ernst E. Herbal medicines for treatment of bacterial infections: a review of controlled clinical trials. J Antimicrob Chemother 2003; 51(2):241-46
23. Oguwike FN, Offor CC, Nwadighoha AN, Ebede SO. Evaluation of Efficacy of Cabbage Juice (Brassica Oleracea Linne) As Potential Antiulcer Aggent and Its Effect on the Haemostatic Mechanism of Male Albino Wistar Rats. J Dental Med Sci 2014; 13:92-97.

24. Abdel AMM, Abdulsalam MAA, Ibrahim NDG. Effect of aqueous extract of glove (Syzygium aromaticum) on normal gastric secretions and indomethacin induced gastric ulcer in rats. Sci J Al-Azhar Med Fac 2006; 27(2):2217-25.

25. Adami R, Maraggi UE, Turba C. Pharmacological research on gefernate, a new synthetic isoprenoid with anti-ulcer activity. $\mathrm{Br} J$ Pharmacol 1997; 120:581-86.

26. Drury RAB, Wallinglon EA. Light microscope and slide preparation. Carleton's histological technique. London, Oxford University Press, $1980 ; 269$.

27. Azamthulla M, Asad1 M, Prasad VS. Antiulcer activity of allium sativum bulb juice in rats. Saudi Pharmaceut J 2009; 17: 70-7.

28. Borra SK, Lagisetty RK, Mallela GR. Anti-ulcer effect of Aloe vera in non-steroidal antiinflammatory drug induced peptic ulcers in rats. African J Pharmacol 2011; 5(16):1867-71.

29. Adnan M, Ullah I, Tariq A, Murad W, Azizullah A, Khan AL, Ali N. Ethnomedicine use in the war affected region of northwest Pakistan. J Ethnobiol Ethnomed 2014; 10:1-16

30. Bussmann RW, Sharon D. Traditional medicinal plant use in Northern Peru: tracking two thousand years of healing culture. J Ethnobiol Ethnomed 2006, 2:47.

31. Dai XP, Li JB, Liu ZQ, Ding X, Huang CH, Zhou $B$. Effect of Jianweiyuyang granule on gastric ulcer recurrence and expression of VEGF mRNA in the healing process of gastric ulcer in rats. World $\mathrm{J}$ Gastroenterol 2005; 11:5480-84.

32. Ling JH, Li JB, Shen DZ, Zhou B. Nuclear factorkappaB mRNA and protein expression in stomach tissue of rats with gastric ulcer recurrence and effect of jianwei yuyang granule on its expression. Zhongguo Zhongxiyi Jiehe Zazhi 2006; 26:228.

33. Bi WP, Man HB, Man MQ. Efficacy and safety of herbal medicines in treating gastric ulcer: A review. World J Gastroenterol,2014;20(45): 17020.

34. Calvo TR, Lima ZP, Silva JS, et al.; Constituents and antiulcer effect of Alchornea glandulosa: activation of cell proliferation in gastric mucosa during the healing process. Biol Pharm Bull 2007; 30: 451-459. 